Heins, M., Schellevis, F., Rijken, M., Hoek, L. van der, Korevaar, J. Determinants of increased primary health care use in cancer survivors. Journal of Clinical Oncology: 2012, 30(33), 41554160

\begin{tabular}{|l|l|}
\hline $\begin{array}{l}\text { Postprint } \\
\text { Version }\end{array}$ & 1.0 \\
\hline Journal website & http://jco.ascopubs.org/content/30/33/4155.abstract \\
\hline Pubmed link & $\underline{\text { http://www.ncbi.nlm.nih.gov/pubmed/23071230 }}$ \\
\hline DOI & $10.1200 / J C O .2012 .41 .9101$ \\
\hline
\end{tabular}

This is a NIVEL certified Post Print, more info at http://www.nivel.eu

\title{
Determinants of Increased Primary Health Care Use in Cancer Survivors
}

\author{
Marianne Heins, Francois SCHelleVis, MieKe RiJKen, LuCAS VAN DER HoEK, AND \\ JOKE KOREVAAR
}

\begin{abstract}
A B S T R A C T
Purpose: The number of cancer survivors is increasing, and patients with cancer often experience long-lasting consequences of cancer and its treatment. Because of the variety of health problems and high prevalence of comorbidity, primary care physicians (PCPs) seem obvious candidates to take care of these patients, and insight into primary health care (PHC) use of cancer survivors is needed. We aimed to find determinants for PHC use in cancer survivors.

Methods: Using data from the Netherlands Information Network of Primary Care, we determined the volume of PHC use in 1,256 adult patients with breast cancer, 503 patients with prostate cancer, and 487patients with colorectal cancer 2 to 5 years after diagnosis and compared this with age- and sex-matched controls without cancer from the same practice. We also examined whether age, comorbidity, and time since diagnosis were related to PHC use.

Results: The mean annual number of primary care contacts was increased compared with control patients by $24 \%$ in patients with breast cancer $(\mathrm{P}<.001)$ and by $33 \%$ in patients with prostate cancer $(\mathrm{P}<.001)$. This difference remained constant between 2 and 5 years after diagnosis.

In patients with colon cancer, the difference with controls tended to decrease with age (12\%per 10 years; $\mathrm{P}=.005$ ).

Conclusion: PHC use is significantly increased 2 to 5 years after diagnosis of cancer, especially in younger patients without a chronic disease. Given the expected increase in cancer survivors, PCPs should prepare themselves for this increasing amount of aftercare. The development of multidisciplinary care standards for cancer survivors could be helpful.
\end{abstract}

\section{INTRODUCTION}

Cancer is a widespread disease, with an estimated12.7 million new patients worldwide in $2008 .{ }^{1}$ Fortunately, treatment options are improving, so more patients are still alive 5 years after diagnosis. ${ }^{2}$ In the Netherlands, 5-year survival for all cancer types increased from $47 \%$ in 1989 to 1993 to 59\% in 2004 to2008. ${ }^{3}$ Many patients with cancer will experience negative consequences of cancer and its 
Heins, M., Schellevis, F., Rijken, M., Hoek, L. van der, Korevaar, J. Determinants of increased primary health care use in cancer survivors. Journal of Clinical Oncology: 2012, 30(33), 41554160

treatment, sometimes several years after completion of active treatment. Common consequences include fatigue, musculoskeletal symptoms, and sexual problems, which often lead to problems with work and may restrict physical and social activities. ${ }^{4}$ Health related quality of life is significantly lower in cancer survivors, when compared with persons who have never been diagnosed with cancer. ${ }^{5}$ This means that cancer is increasingly becoming a chronic disease requiring long-lasting attention of health care providers.

In many Western countries, such as the United Kingdom and the Netherlands, the primary care physician (PCP) is the main health care provider and gatekeeper to secondary care. Once active specialist treatment for cancer has been completed, the role of primary health care (PHC) will become more prominent in aftercare. Because of the relatively older age of patients with cancer, they will often have comorbidities that need to be taken into account. ${ }^{6}$ Coordinating care for these comorbidities is one of the main tasks of PCPs. Moreover, psychological and social aspects may also play a role in the after care of patients with cancer and need special attention. ${ }^{4}$ With their generalist and broad view, accessibility, and wide network of health care providers, PCPs seem obvious candidates to manage aftercare of cancer survivors.

Given the expected increase in long-term cancer survivors, insight into the volume and determinants of PHC use of cancer survivors is important. Only a few studies have actually looked at PHC consumption of patients with cancer in the years after treatment. They showed conflicting results as to whether cancer survivors need more care after active in-hospital treatment compared with age- and sex matched controls. A study from France found that Hodgkin lymphoma survivors at least 4 years after diagnosis made more visits to their PCP than controls without a history of cancer. ${ }^{7}$ Snyder et $\mathrm{al}^{8}$ found the same for breast cancer survivors 1 to 5 years after diagnosis. Finally, a study from the United Kingdom concerning patients with breast, colorectal, and prostate cancer found that PHC use was significantly increased up to at least 5 years from diagnosis, after which consultation rates declined slowly. ${ }^{9}$

However, it is not clear whether more patients visit their PCP or whether the same patients make more visits. Three studies found that more than 5 years after the diagnosis of cancer, the percentage of patients visiting their PCP was increased, at least in certain cancer types like prostate cancer and Hodgkin lymphoma.

${ }^{7,10,11}$ However, two other studies in long-term breast cancer survivors found no increase in the percentage of patients visiting their PCP. ${ }^{12,13}$ Overall, PHC use in cancer survivors seems increased, but few studies have explored determinants of this increased PHC use. Only Khan et $\mathrm{al}^{9}$ considered time since diagnosis. However, PHC use maybe primarily increased in the elderly or those with a chronic disease, because they are probably more vulnerable to the effects of cancer and its treatment.

Alternatively, PHC use may be increased in younger and other wise healthy patients with cancer because they usually would not visit their PCP. Using data from a large Dutch primary care-based registry, we aimed to determine the number of PHC contacts in adults 2 to 5 years after diagnosis of breast, prostate, or colorectal cancer. In this period, most patients have finished active treatment for cancer, but PHC use is most likely still increased. ${ }^{9}$ We examined factors that might influence PHC use, such as type of cancer, time after diagnosis, age, and presence of a chronic disease, and determined whether these factors affected the difference between patients with cancer and noncancer controls. 
Heins, M., Schellevis, F., Rijken, M., Hoek, L. van der, Korevaar, J. Determinants of increased primary health care use in cancer survivors. Journal of Clinical Oncology: 2012, 30(33), 41554160

\section{METHODS}

\section{Database}

For this study, data from the Netherlands Information Network of Primary Care (LINH) were used. Data are collected in a nationally representative network of approximately 92 practices spread throughout the Netherlands. ${ }^{14}$ Twice a year, data are extracted from the electronic medical records (EMRs)used in the practices. PCPs routinely record data on all patient contacts, including diagnoses, referrals, and prescriptions. Diagnoses are coded using the International Classification of Primary Care (ICPC). Contacts may be regular consults at the practice, telephone consults, or home visits. In the Netherlands, when a patient is too ill or disabled to visit the practice, the PCP visits the patient at home. Telephone consults are mostly for follow-up after a practice visit. Medication request refills were excluded from the telephone consults. In the Netherlands, all inhabitants are obligatorily insured for standard medical care and listed with a PCP. ${ }^{15}$

\section{Study Population}

Wes elected all patients diagnosed with breast cancer, prostate cancer, or colorectal cancer between January 2001 and December 2006 based on a recorded ICPC code in their EMR. We selected these cancer types based on their relatively high incidence and survival. Patients had to be at least 18 years at diagnosis and have at least 3 years of follow-up available starting from diagnosis.

\section{[TABLE1].}

We did not want to obscure our findings with patients who were in the diagnostic trajectory or active treatment phase instead of the aftercare phase.

Patients were excluded when another type of cancer was diagnosed within 5years of the index cancer. We also excluded the data before the occurrence of the second cancer because patients may experience symptoms before diagnosis.

The Dutch clinical guideline "Recovery After Cancer" ${ }^{\text {"15a }}$ recommends that when no signs of recurrence or health effects of treatment are present 1 year after completion of active treatment, the patient is referred back to the PCP.

Two years after diagnosis of cancer, most survivors, free of active disease, will have been transitioned to the PCP. We did not specifically exclude patients in the terminal phase because this phase is difficult to determine in our data and patients may have died as a result of causes other than cancer.

For each patient, we selected two controls from the same practice without a known diagnosis of cancer in their EMR, who were of the same age (_5years) and sex. Patients and controls were matched on age at the date of diagnosis, and controls also had to have at least 3 years of data available starting from the date of diagnosis of the patient.

Available data on contacts with the practice and diagnoses from inclusion up to 5 years after diagnosis or inclusion date were extracted. Only data from regular patients (ie, those who had been registered in the practice during the whole year) and practices that had provided data for at least 48 weeks per year and fulfilled quality requirements (accuracy of diagnostic codes and type of contact in at least $50 \%$ of the years) were selected.

The study was carried out according to the precepts of the Helsinki Declaration, Dutch legislation on privacy, and the regulations of the Dutch Data Protection 
Heins, M., Schellevis, F., Rijken, M., Hoek, L. van der, Korevaar, J. Determinants of increased primary health care use in cancer survivors. Journal of Clinical Oncology: 2012, 30(33), 41554160

Authority. According to Dutch legislation, obtaining informed consent is not necessary for observational research.

\section{Chronic Disease}

Chronic disease was defined as the presence of an ICPC code in the EMR from one of eight clusters of chronic diseases (ischemic heart disease/heart failure, cerebrovascular accident/transient ischemic attack, chronic obstructive pulmonary disease/asthma, rheumatoid arthritis/osteoarthritis, diabetes, previous malignancy, anxiety disorder, and depressive disorder). These diseases were selected from a long list of chronic diseases ${ }^{16}$ based on their prevalence in the general population and their potential impact on PHC use. We used an existing coding table to convert the original ICPC-2 codes to ICPCcodes. ${ }^{17}$ ICPC codes were derived from the EMRs. Prevalence rates of these diseases in the first 2 years after inclusion were calculated, because we expected that during a 2-year period most patients with a chronic disease will have a PHC contact.

\section{Statistical Analyses}

First, we determined the volume of PHC use in patients with cancer and controls. On the basis of the number of contacts with the practice between 2and 5 years after diagnosis and the length of follow-up, an annual contact rate was calculated, which was compared between patients and matched controls.

Next, several factors that could influence PHC use were examined (ie, age, presence of a chronic disease, and time after diagnosis). The impact of these factors was tested using multivariate negative binomial regressionanalyses. ${ }^{18}$ We chose this type of regression analysis because our outcome variable, the annual number of primary care visits, is a rate and this type of regression predicts the rate of an event. Per cancer type, we built a model with patient/control, age, and chronic disease as independent variables. To assess the effect of age and chronic disease on the difference between patients and controls, we added two interaction variables (age $\mathrm{X}$ patient/control and chronic disease X patient/control). We built another model with patient/control, year after diagnosis, and an interaction variable as independent variables to determine the effect of time since diagnosis on the difference between patients and controls. To correct for repeated measurement sin the latter model, we relaxed the assumption of independence of observations in calculating the variance-covariance estimate (vce) using the option vce (cluster). For these analyses, only patient and control triads in which all had at least 5 years of follow-up were selected.

All analyses were stratified by cancer type. Analyses were performed using STATA SE version 11.2 (STATA, College Station, TX). To correct for multiple comparisons, $P=.001$ was used for significance testing.

\section{RESULTS}

In our sample, between January 2001 and December 2006, 2,387adult patients were diagnosed with breast cancer, 1,251 patients were diagnosed with prostate cancer, and 1,392 patients were diagnosed with colorectal cancer. We excluded 571 patients because they were diagnosed with another type of cancer within 5 years after the index cancer diagnosis (breast cancer, $n=215$; prostate cancer, $n=191$; colorectal cancer, $n=165$ ), and we excluded 2,213 patients because they did not have at least 3 years of follow-up data available after diagnosis (breast cancer, $\mathrm{n}=916$; prostate cancer, $\mathrm{n}=557$; colorectal cancer, $\mathrm{n}=740$ ). 
Heins, M., Schellevis, F., Rijken, M., Hoek, L. van der, Korevaar, J. Determinants of increased primary health care use in cancer survivors. Journal of Clinical Oncology: 2012, 30(33), 41554160

\section{[FIGURE 1].}

In total, 1,256 patients with breast cancer, 503 patients with prostate cancer, and 487 patients with colorectal cancer were matched to two controls from the same practice with the same age ( \pm 5 years)and sex. Baseline characteristics of patients and controls are listed in Table 1. Patients with breast and prostate cancer more often had a chronic disease than the matched controls (44\% v 38\% and 58\% v $47 \%$, respectively; $P<.001)$. Compared with controls, patients with breast cancer more often had diabetes (10\% v 8\% in controls; $P=.047)$ and depressive disorder (6\% v 5\% in controls; $P=.02$ ), whereas patients with prostate cancer more often had arthritis $(10 \% \vee 5 \%$ in controls; $P<.001)$. Patients can obviously have more than one chronic disorder. Post hoc analyses showed that patients with breast and prostate cancer also had a higher risk of having multiple chronic diseases (Fig 1); this risk increased with the number of disorders, as shown by a trend analysis $(z=2.99$, $P=.003$; and $z=4.08, P<.001$,respectively). This trend was not found for patients with colorectal cancer $(\mathrm{z}=1.64, P=.10)$.

\section{[TABLE 2].}

The mean annual number of contacts was increased by $24 \%$ in patients with breast cancerandby33\%in patients with prostate cancer compared with controls (Table 2). The percentage of patients who had at least one contact with their PCP during the follow-up period tended to be higher in patients with breast cancer and colorectal cancer than in controls ( $87 \% v 84 \%, P=.01$; and $88 \% v 83 \%, P=.02$, respectively). This was mostly because of the percentage of patients with a home visit or telephone consultation.

The difference in PHC use between patients and controls did not decline between 2 and 5 years after diagnosis (Fig 2). This was confirmed by results of binomial regression (breast cancer incidence rate ratio [IRR], 1.001/yr, $P=.97$, which would indicate a $0.1 \%$ increase per year; prostate cancer IRR, 0.99/yr, $P=.85$; and colorectal cancer IRR, 0.97/yr, $P=.53$ ).

In Figure 3, the annual number of contacts, as predicted by multivariate binomial regression, is presented for patients with cancer and noncancer controls with and without a chronic disease. In patients with colorectal cancer, the difference with noncancer controls decreased with age (12\% per 10 years, $P=.005)$. In patients with breast cancer and colorectal cancer, the difference with noncancer controls tended to be smaller in persons with a chronic disease $(12 \%, P=.09$; and $19 \%, P=.07$, respectively).

\section{DISCUSSION}

Our results show that PHC use by patients with breast, prostate, and colorectal cancer is increased 2 to 5 years after diagnosis (by 24\%, 33\%,and 15\%, respectively, compared with controls) and does not decline within this period. In both patients with cancer and controls, PHC use is highest in older patients and in those with a chronic disease. The difference between patients with colorectal cancer and noncancer controls, however, is most prominent in younger patients and those without a chronic disease (ie, patients who would usually have few PHC visits). The increase in PHC use we found is larger than in the study by Snyder et al, ${ }^{8}$ who only found a 6\%increase in PHC use in US patients with breast cancer up to 5 years after diagnosis. This may be a result of differences in health care systems, because in 
Heins, M., Schellevis, F., Rijken, M., Hoek, L. van der, Korevaar, J. Determinants of increased primary health care use in cancer survivors. Journal of Clinical Oncology: 2012, 30(33), 41554160

the Netherlands, every in habitant is obligatorily registered with a PCP. Khan et al ${ }^{9}$ studied PHC use in the United Kingdom, which has a health care system much more similar to that in the Netherlands. Although they found higher consultation rates, the percentage of increase in PHC use was similar to our study for both patients with prostate cancer and colorectal cancer (39\%and 12\%, respectively). In patients with breast cancer, the percentage of increase was smaller than in our study (11\%). However, the follow-up period in the study by Khanet $\mathrm{al}^{9}$ was up to 20 years, and the difference between breast cancer survivors and controls declined 5years after diagnosis.

\section{[FIGURE 2 EN 3].}

The increase in PHC use in patients with colorectal cancer seemed most prominent in younger patients and those without a chronic disorder. Also in patients with breast cancer, the difference with noncancer controls tended to be larger in those without a chronic disorder. Maybe patients with a chronic disorder combine care for their comorbid disorder and cancer-related health problems in one contact. Interestingly, the difference between patients with prostate cancer and controls was not affected by age or presence of a chronic disorder. These factors may have less influence in this relatively old group with a high prevalence of chronic disease. Alternatively, this may be related to the nature of the disease or treatment.

For the individual patient, the increase we found may not be clinically significant, but as the number of long-term cancer survivors continues to grow, this may mean a significant increase in work pressure for PCPs. Therefore, they should prepare themselves for this task. Although our results indicate that PCPs are already providing aftercare for cancer survivors, confidence that PCPs are capable to care for patients with cancer is not high, both in oncologists and PCPsthemselves. ${ }^{19}$ When oncology specialists and PCPs explicitly discuss the follow-up plan for the patient at the end of treatment, this will improve agreement between both medical practitioners and lead to better follow-up care for the patient. ${ }^{20}$ Good communication between oncology specialists and PCPs may thus improve the quality of care for cancer survivors. ${ }^{21}$ We used a large PHC registry with systematically collected data. This enabled us to study a large sample of patients over a relatively long period and minimized selection bias, because all patients in the participating practices were included. The EMRs on which our data were based could be incomplete. However, practices also used these files for their reimbursement claims with insurance companies, which makes it less likely that practices did not record a contact. Moreover, it is not likely that PCPs' recording behavior will differ between patients with and without cancer. Furthermore, practices not meeting quality criteria(accuracy of diagnostic codes and type of contact) in at least $50 \%$ of the years they participated were excluded.

Although validity of cancer diagnoses in a PHC database is generally high, with a median of $95 \%$ of the diagnoses confirmed by external validation, ${ }^{22}$ cancer diagnoses and date of diagnosis were not verified. We may have misclassified some patients as cancer survivors or controls. Additionally, we only had information for the years the practices participated in the LINH network. Therefore, we could not verify whether patients had received a diagnosis of cancer before their PCP started participating in LINH, so some cancer survivors may have mistakenly been included as controls. 
Heins, M., Schellevis, F., Rijken, M., Hoek, L. van der, Korevaar, J. Determinants of increased primary health care use in cancer survivors. Journal of Clinical Oncology: 2012, 30(33), 41554160

This may have diluted the effect of cancer on PHC use, and thus, the real difference between patients and controls may even be larger.

It would have been interesting to assess the effects of factors such as marital status, educational level, and treatment characteristics, but we were limited to the information provided in the database.

We did not exclude the terminal phase, which one may argue is not part of regular aftercare. Because PHC use is considerably increased during the terminal phase, this may have enlarged the difference between patients with cancer and matched controls. However, the number of patients who died within our follow-up period was relatively low (184 patients with cancer [8\%] and 181 matched controls[4\%]), so it seems reasonable to assume that the amount of over estimation is limited.

In conclusion, PHC use is significantly increased 2 to 5 years after the diagnosis of breast, prostate, or colorectal cancer. In breast and colorectal cancer, this increase is most prominent in younger patients and those without a chronic disease, whereas in prostate cancer, this increase is independent of age and presence of comorbidity. As the number of long-term cancer survivors continues to grow, care for these patients will increase work pressure on PCPs. PCPs should prepare themselves for this task. The development and implementation of multidisciplinary care standards could stimulate communication between PCPs and oncologists and give PCPs support in caring for cancer survivors.

\section{REFERENCES}

1. Jemal A, Bray F, Center MM, et al: Global cancer statistics. CA Cancer J Clin 61:69-90, 2011

2. Verdecchia A, Francisci S, Brenner H, et al: Recent cancer survival in Europe: A 2000-02 period analysis ofEUROCARE-4 data. Lancet Oncol 8:784-796, 2007

3. Siesling S, Visser O, Luth TK, et al: [Survival of adult cancer patients in the Netherlands increases: 5-yearsurvival increased with 12\% between 1989-1993 and2004-2008]. Ned Tijdschr Geneeskd 155:A3169, 2011

4. Stein KD, Syrjala KL, Andrykowski MA: Physicaland psychological long-term and late effects of cancer. Cancer 112:2577-2592, 2008

5. Clauser SB, Arora NK, Bellizzi KM, et al: Disparities in HRQOL of cancer survivors and noncancer managed care enrol lees. Health Care Financ Rev 29:23-40, 2008

6. Ogle KS, Swanson GM, Woods N, et al:Cancer and comorbidity. Cancer 88:653-663, 2000

7. Joly F, Henry-Amar M, Arveux P, et al: Latepsychosocial sequelae in Hodgkin's disease survivors:A French population-based case-control study. J Clin Oncol 14:2444-2453, 1996

8. Snyder CF, Frick KD, Peairs KS, et al: Comparing care for breast cancer survivors to noncancer controls: A five-year longitudinal study. J Gen Intern Med 24:469-474, 2009

9. Khan NF, Watson E, Rose PW: Primary care consultation behaviours of long-term, adult survivors ofcancer in the UK. Br J Gen Pract 61:197-199, 2011

10. Mols F, Helfenrath KA, Vingerhoets AJ, et al:Increased health care utilization among long-term cancer survivors compared to the average Dutch population: A population-based study. Int J Cancer121:871-877, 2007

11. Nord C, Mykletun A, Thorsen L, et al: Selfreported health and use of health care services inlong-term cancer survivors. Int J Cancer 114:307-316, 2005

12. Peuckmann V, Ekholm O, Sjøgren $P$, et al Health care utilisation and characteristics of longterm breast cancer survivors: Nationwide survey in Denmark. Eur J Cancer 45:625633, 2009

13. van de Poll-Franse L, Mols F, Vingerhoets AJ, et al: Increased health care utilisation among 10-yearbreast cancer survivors. Support Care Cancer 14:436-443, 2006

14. Nederlands Instituut Voor Onderzoek van de Gezondheidszorg: Representativiteit van $\mathrm{LINH}$. 
Heins, M., Schellevis, F., Rijken, M., Hoek, L. van der, Korevaar, J. Determinants of increased primary health care use in cancer survivors. Journal of Clinical Oncology: 2012, 30(33), 41554160

http://www.nivel.nl/representativiteit-van-linh

15. Schafer W, Kroneman M, Boerma W, et al: The Netherlands: Health system review. Health Syst Transit 12:v-xxvii, 1-228, 2010

15a. Herstel na kanker [Recovery after cancer],2011. http://www.oncoline.nl/herstel-nakanker

16. O'Halloran J, Miller GC, Britt H: Defining chronic conditions for primary care with ICPC-2.

Fam Pract 21:381-386, 2004

17. Hoeymans N, Schellevis F: [Selection of chronic diseases], in Volksgezondheid Toekomst Verkenning, Nationaal Kompas Volksgezondheid. Bilthoven, the Netherlands, Rijksinstituut voor Volksgezondheid en Milieu, 2011

18. Lawless JF: Negative binomial and mixed Poisson regression. Can J Stat 15:209-225, 1987

19. Potosky AL, Han PK, Rowland J, et al: Differences between primary care physicians' and oncologists' knowledge, attitudes and practices regarding the care of cancer survivors. J Gen Intern Med26:1403-1410, 2011

20. Cheung WY, Neville BA, Earle CC: Associations among cancer survivorship discussions, patient and physician expectations, and receipt of follow-up care. J Clin Oncol 28:2577-2583,2010

21. Grunfeld E, Earle CC: The interface between primary and oncology specialty care: Treatment through survivorship. J Natl Cancer Inst Monogr2010:25-30, 2010

22. Herrett $E$, Thomas SL, Schoonen WM, et al: Validation and validity of diagnoses in the General Practice Research Database: A systematic review. Br J Clin Pharmacol 69:4-14, 2010 
Heins, M., Schellevis, F., Rijken, M., Hoek, L. van der, Korevaar, J. Determinants of increased primary health care use in cancer survivors. Journal of Clinical Oncology: 2012, 30(33), 4155 4160

TABLES AND FIGURES

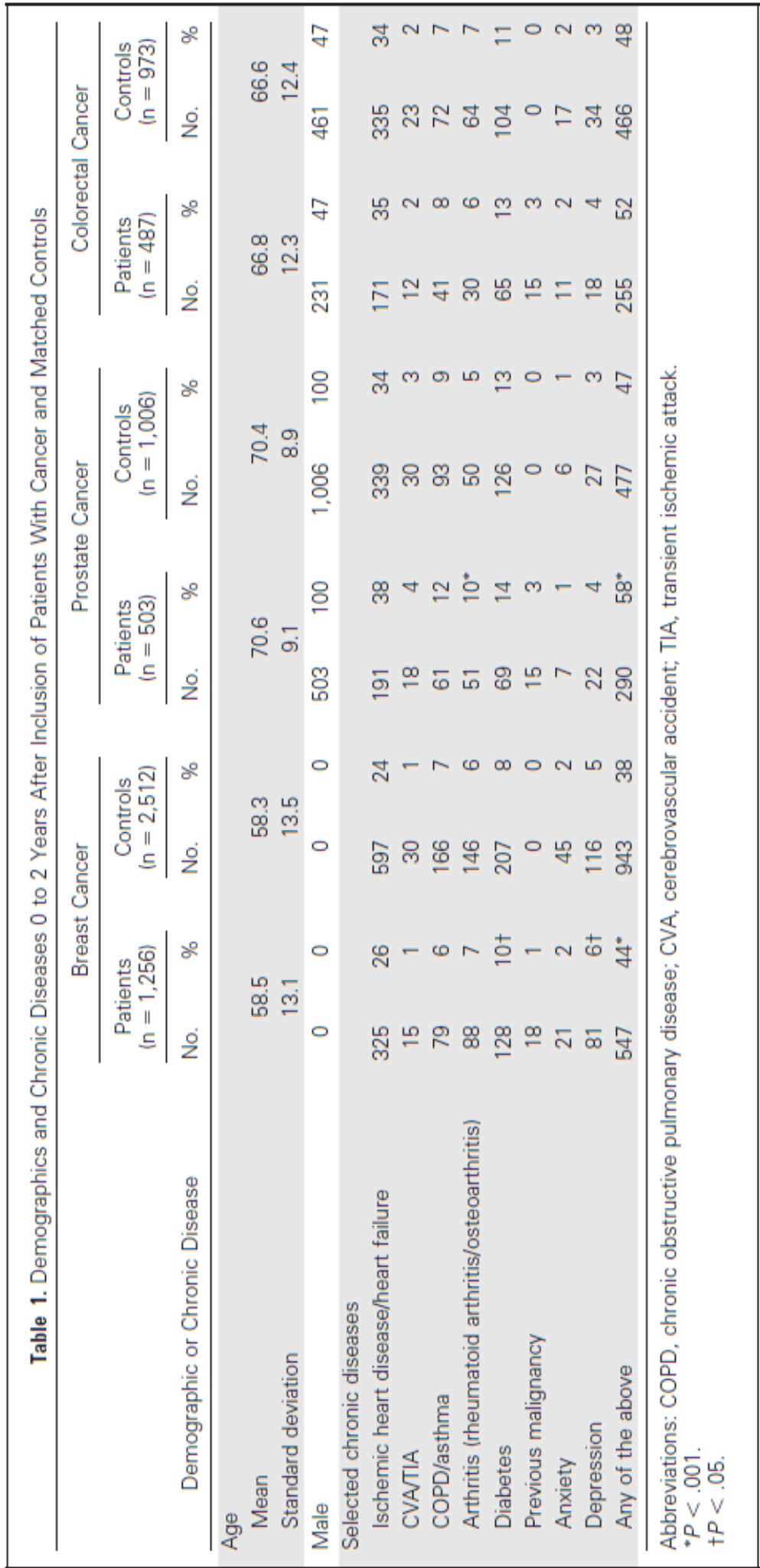


Heins, M., Schellevis, F., Rijken, M., Hoek, L. van der, Korevaar, J. Determinants of increased primary health care use in cancer survivors. Journal of Clinical Oncology: 2012, 30(33), 4155 4160

Fig 1. Number of chronic diseases in patients with (A) breast cancer, (B) prostate cancer, and (C) colorectal cancer and noncancer controls.

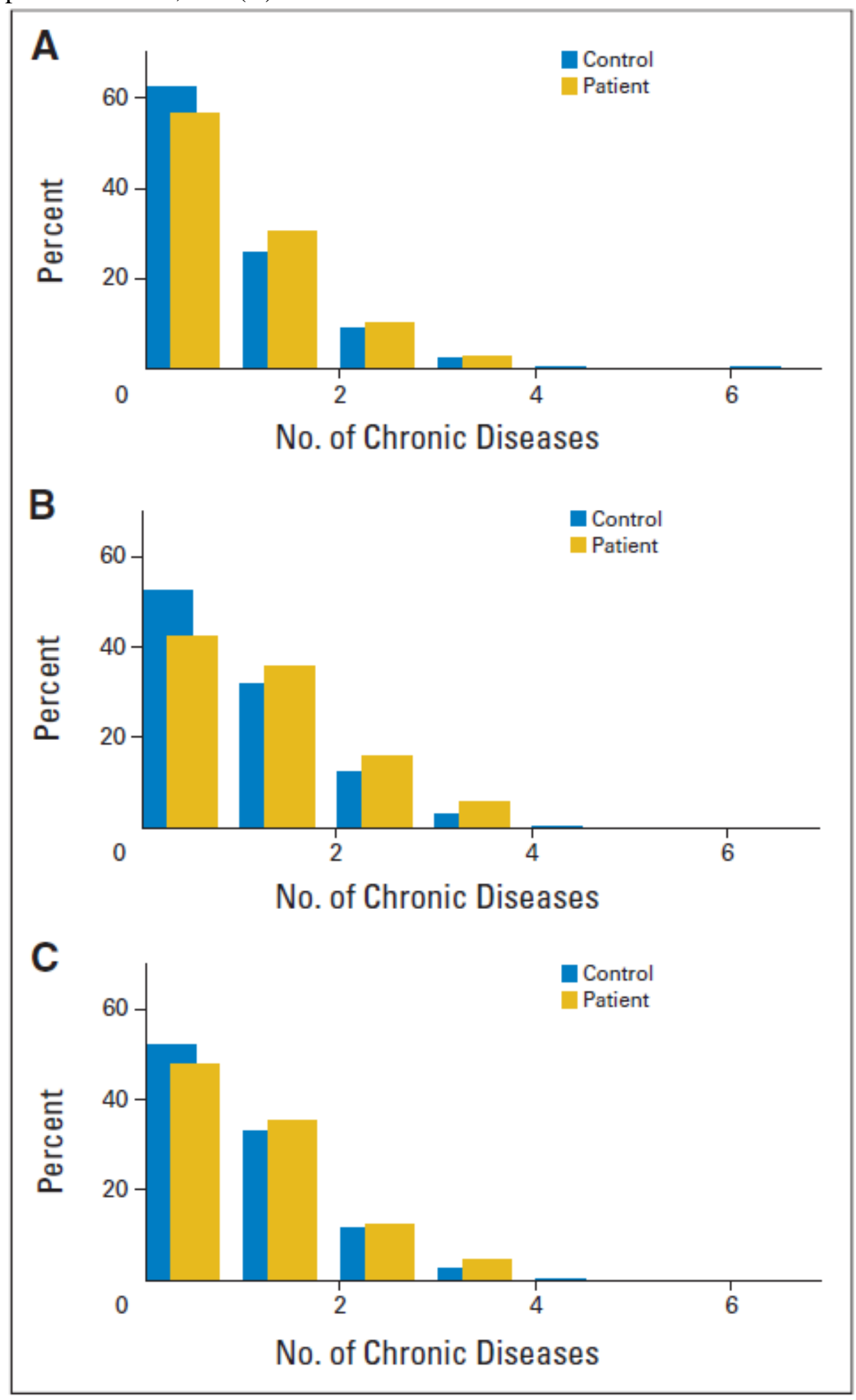


Heins, M., Schellevis, F., Rijken, M., Hoek, L. van der, Korevaar, J. Determinants of increased primary health care use in cancer survivors. Journal of Clinical Oncology: 2012, 30(33), 4155 4160

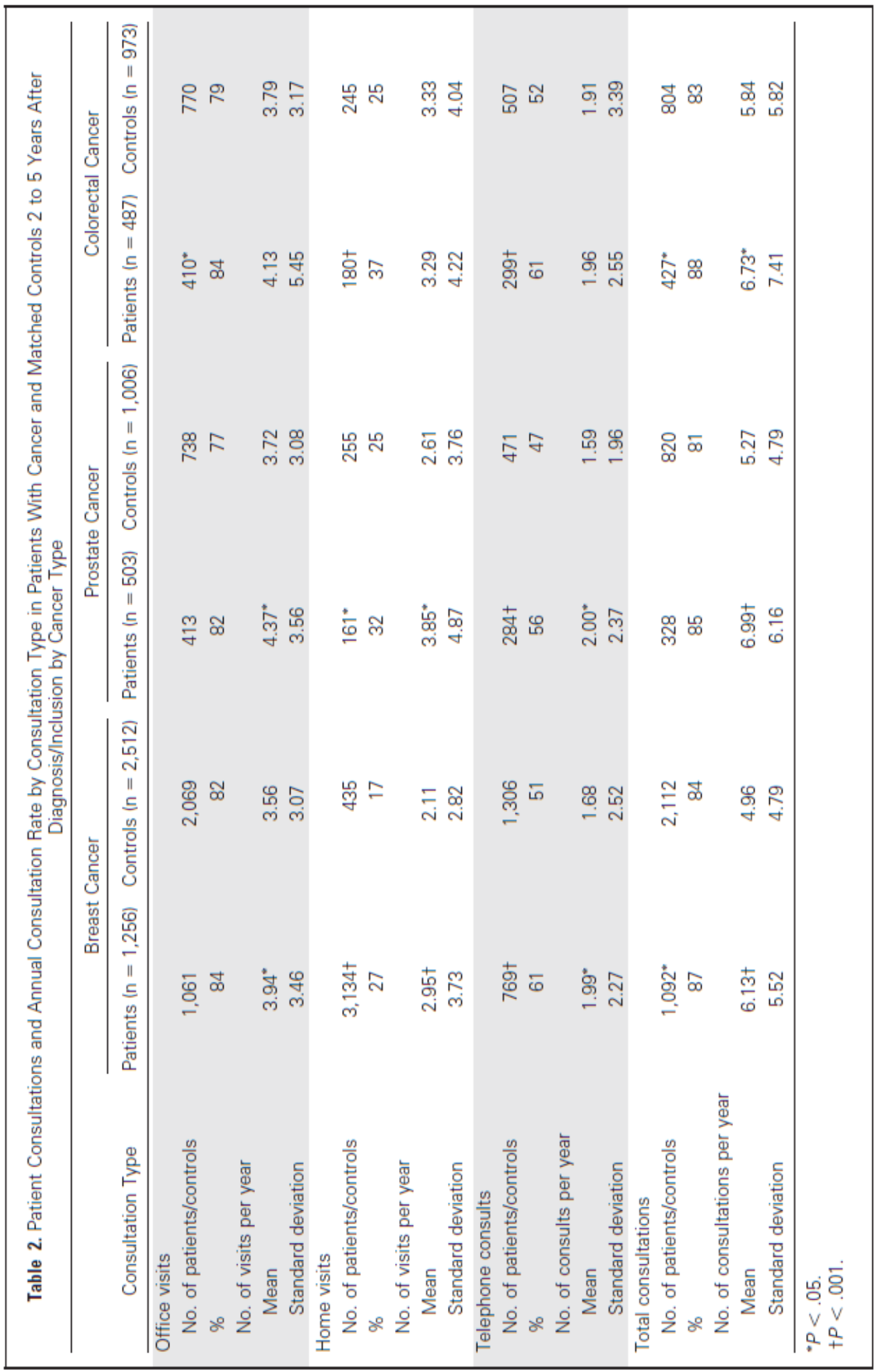


Heins, M., Schellevis, F., Rijken, M., Hoek, L. van der, Korevaar, J. Determinants of increased primary health care use in cancer survivors. Journal of Clinical Oncology: 2012, 30(33), 41554160

Fig 2. Mean number of primary health care contacts (A) 2 to 3 years, (B) 3 to 4 years, and (C) 4 to 5 years after inclusion of patients with cancer and matched controls with at least 5 years of follow-up. PCP, primary care physician.

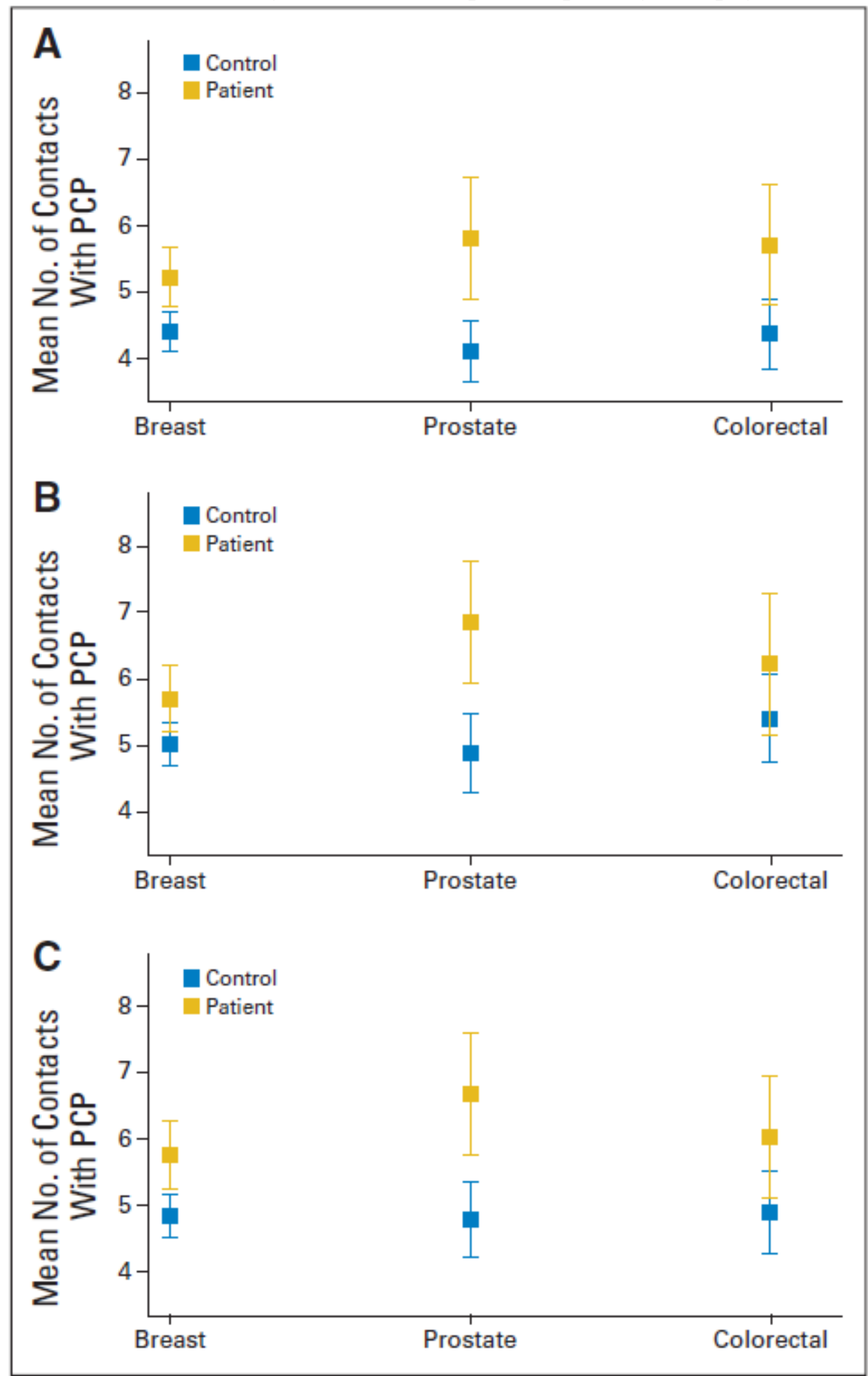


Heins, M., Schellevis, F., Rijken, M., Hoek, L. van der, Korevaar, J. Determinants of increased primary health care use in cancer survivors. Journal of Clinical Oncology: 2012, 30(33), 41554160

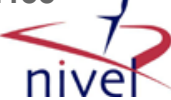

Fig 3. Predicted yearly number of primary care contacts by age for patients with (A) breast cancer, (B) prostate cancer, and (C) colorectal cancer and matched controls with and without a chronic disease 2 to 5 years after diagnosis/inclusion.

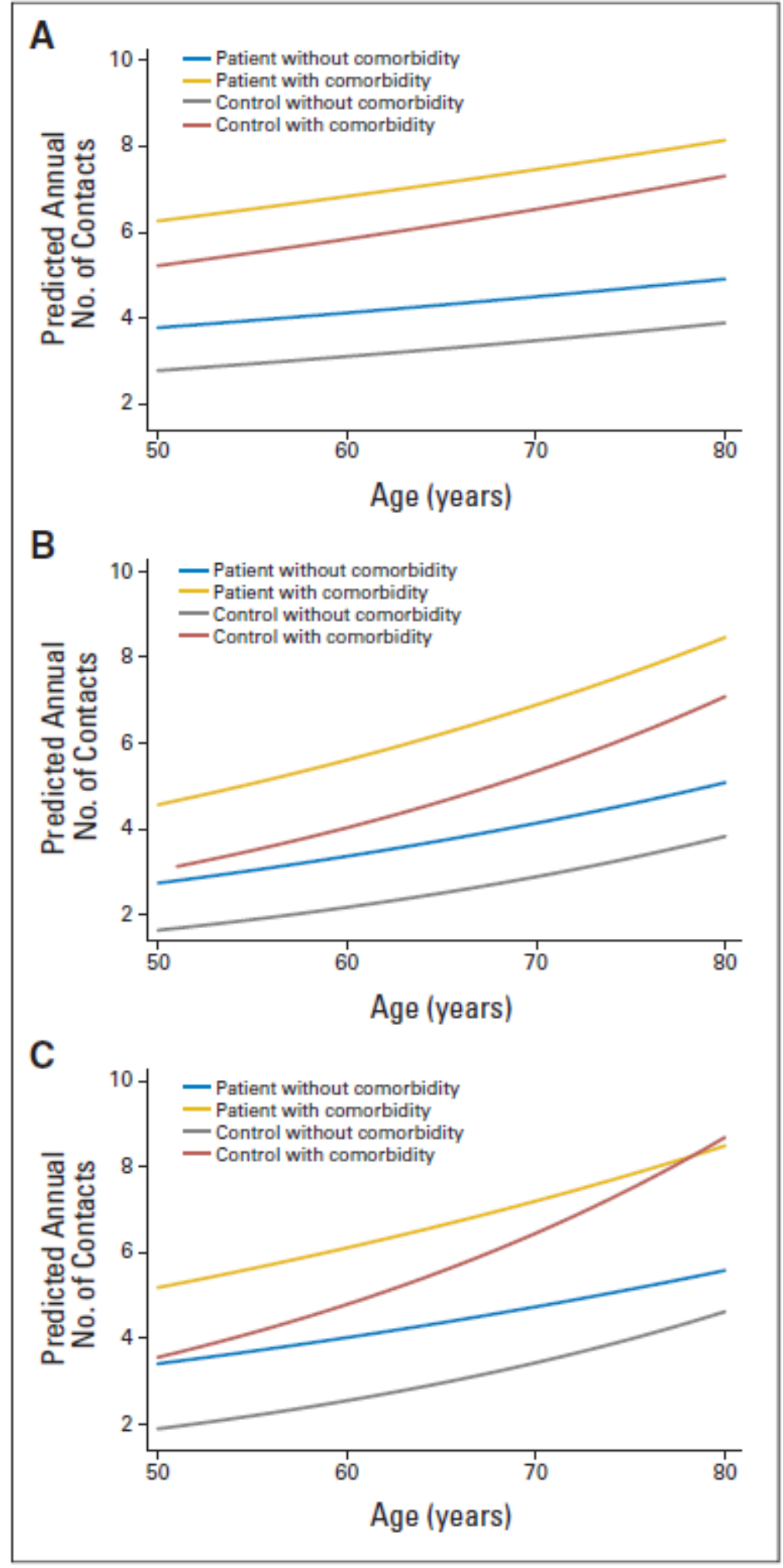

